\title{
Jameson e o pós-modernismo
}

\author{
Giovanna Henrique Marcelino ${ }^{1}$
}

\begin{abstract}
RESUMO: O presente artigo visa expor, de maneira panorâmica, a interpretação de Fredric Jameson sobre o pós-modernismo. O objetivo central é retraçar como este conceito foi usado pelo autor nos anos $1980 \mathrm{em}$ seu esforço de periodizar o capitalismo contemporâneo e mapear uma série de redefinições sistêmicas e mutações significativas na vida cultural, social e subjetiva, cada vez mais centradas em experiências fragmentadas e "presentificadas". Para tanto, serão analisados, sobretudo, dois ensaios que condensam os diagnósticos do autor: Periodizando os anos 60 e Pós-modernismo, a lógica cultural do capitalismo tardio, ambos escritos em 1984. Com isso, pretende-se apurar como a obra de Jameson, em seu esforço próprio de atualizar a teoria marxista, levanta elementos originais para se pensar a sociedade capitalista contemporânea e seus principais sintomas sociais.
\end{abstract}

Palavras-chave: Fredric Jameson. marxismo. pós-modernismo. capitalismo. sujeito.

\section{Jameson and postmodernism}

\begin{abstract}
This article aims to give a panoramic view of Fredric Jameson's interpretation of postmodernism. The central objective is to retrace how this concept was used by the author in the 1980s in his effort to periodize contemporary capitalism and map a series of systemic redefinitions and significant changes in social, cultural and subjective life, increasingly marked by fragmented and 'presentified' experiences. Therefore, two essays that condense the author's diagnoses will be analyzed: Periodizing the 60s and Postmodernism, the cultural logic of late capitalism, both written in 1984. With this, it is intended to ascertain how the work of Jameson, in its own effort to update Marxist theory, raises original elements to consider contemporary capitalist society and its main social symptoms.
\end{abstract}

Keywords: Fredric Jameson. Marxism. postmodernism. capitalism. subject.

${ }^{1}$ Doutoranda no Programa de Pós-Graduação em Sociologia da Faculdade de Filosofia, Letras e Ciências Humanas da Universidade de São Paulo (FFLCHUSP). E-mail: giovannahmarcelino@gmail.com. 
$|2|$

Jameson e o pós-modernismo

\section{Jameson y el posmodernismo}

RESUMEN: El presente artículo tiene como objetivo ofrecer una visión panorámica de la interpretación de la posmodernidad desarrollada por Fredric Jameson. Se estudiará cómo este concepto fue utilizado por el autor en la década de 1980, en un esfuerzo por comprender los diferentes momentos del capitalismo contemporáneo y mapear una serie de nuevas definiciones sistémicas y cambios significativos en la vida social, cultural y subjetiva, cada vez más marcadas por experiencias fragmentadas y 'presentificadas'. Para ello se analizarán dos ensayos que condensan los diagnósticos del autor: Periodizar los años 60 y Posmodernismo, la lógica cultural del capitalismo tardío, ambos de 1984. Con esto, se pretende determinar cómo la obra de Jameson, en su propio empeño por actualizar la teoría marxista, presenta elementos originales para pensar la sociedad capitalista contemporánea y sus principales síntomas sociales.

Palabras clave: Fredric Jameson. marxismo. posmodernismo. capitalismo. sujeto.

\section{Periodizando os anos 1960}

Após seus estudos sobre a tradição marxista-hegeliana da dialética, sobre as teorias do formalismo russo e do estruturalismo francês e sobre as diferentes correntes interpretativas em voga na crítica literária nos anos 1970, a linha mestra que passou a orientar o trabalho teórico de Fredric Jameson foi a relação entre marxismo e pós-modernismo (JAMESON, 1985; 1974; 1992a; 1997).

Longe de ser uma ruptura com as proposições iniciais de sua obra, seu interesse pelo tema foi uma consequência lógica, ou ainda, o ponto auge de seus esforços anteriores de introduzir, defender e desenvolver a teoria marxista e suas categorias na academia norte-americana, num diálogo crítico com outras tendências intelectuais. Assim, após ter submetido ao exame correntes como o estruturalismo, o desconstrutivismo e o pósestruturalismo nos anos 1970, Jameson se atém a uma das posições filosóficas que marcou a década posterior, retrabalhando seus alcances e contradições. Além disso, tal movimento complementa, em particular, o esquema que havia exposto em seu livro $\mathrm{O}$ inconsciente político de compreender as lógicas culturais 
específicas de cada modo de produção ${ }^{2}$, de forma a interpretar o surgimento do pós-modernismo como parte da história do capital e de sua lógica de expansão, promovendo, com isso, tanto uma compreensão alternativa às definições dominantes do conceito até aquele momento (Lyotard, Habermas, etc.), como uma atualização do marxismo e de seu diagnóstico do presente histórico.

Jameson publicou extensamente sobre o pós-modernismo durante os anos 1980. Seu primeiro escrito sobre o assunto, o ensaio Pós-modernismo e sociedade de consumo, data de 1982; e sua posição a esse respeito adquiriu ressonância com a publicação, na revista New Left Review, do artigo A lógica cultural do capitalismo tardio (1984), embrião do seu livro Pós-modernismo, a lógica cultural do capitalismo tardio (1991).

Um ponto de partida possível para compreender a interpretação apresentada ao longo de seus ensaios é a sua visão sobre os anos 1960. Esta década foi, na definição de Jameson, um período de transição ${ }^{3}$, mais precisamente, o momento em que se processaram as condições para que o pós-modernismo viesse a se tornar uma dominante cultural nos anos 1980 (JAMESON, 2006a, p. 20). Seu argumento é de que ela foi uma espécie de "pré-história" do conceito, na medida em que o pós-modernismo se consolida enquanto uma "lógica cultural do capitalismo" no instante em que a retórica vanguardista da década anterior (presente nas artes, na política, na teoria, etc.) é extinta, sobrando apenas o esvaziamento

\footnotetext{
${ }^{2}$ Para Jameson, o modo de produção capitalista teria passado por três mutações específicas: a do capitalismo de mercado (tal como descrito por Marx), do capitalismo monopolista ou imperialista (descrita por Lenin) e do capitalismo tardio (Mandel), cada uma acompanhada de uma "revolução cultural" e linguística que consolidou formas "de codificação ideológica" específicas (dominantes culturais): o realismo, o modernismo e o pós-modernismo, respectivamente (JAMESON, 1992a, p. 82).

3 Jameson caracteriza um "período de transição" como aquele em que se dá um amplo sentimento de "liberdade histórica", "quando o estilo de vida ainda não assumiu a rigidez de um estilo de época, e quando há uma súbita libertação do velho sem qualquer obrigação correspondente para com o que virá em seu lugar" (JAMESON, 1985, pp. 39-40).
} 
dos pressupostos em que ela estava baseada - a celebração eclética e dispersa do pluralismo, da heterogeneidade e da coexistência de múltiplos grupos sociais fragmentados. Os anos 1980 seriam, assim, o momento de falência "da liberação do corpo, do desejo e dos sentidos que tinha sido um dos 'ganhos' principais das batalhas dos anos 60" (JAMESON, 1997, p. 19), de forma que o pós-modernismo deveria ser entendido justamente como um "substitutivo para os anos 60, e a compensação por seu fracasso político" (JAMESON, 1997, p. 264), tornando-se "a sequência, ou continuação ou realização, do episódio do 'fim da ideologia' dos anos 50" pronunciado pelos ideólogos conservadores da Guerra Fria (JAMESON, 1997, p. 271). Como expõe em outra passagem:

Talvez, de fato, o que se segue após uma autoconsciência de geração tão forte, como a experimentada pelo "pessoal dos anos 60", é, no mais das vezes, um grande desnorteamento. [...] Mesmo a ilusão da festa à fantasia de que falava Marx - vestir as fantasias dos grandes momentos do passado - não é mais possível nesse período a-histórico da história. A combinatoire das gerações parece ter se quebrado no momento em que se confrontou com a seriedade da historicidade e o autoconceito bem diferente de "pós-modernismo" tomou seu lugar (JAMESON, 1997, p. 301).

A concepção de pós-moderno de Jameson, portanto, pressupõe um exame crítico dos rumos que tomaram uma série de processos que insurgiram nos anos 1960 - a emergência dos "novos movimentos sociais", o surgimento de novas tendências na arte, o momento pós-estruturalista na teoria, etc. - afim de entender como a retórica a princípio progressiva das "diferenças" que marcou tais empreendimentos contraditoriamente tornouse funcional à própria dinâmica capitalista. Nesse sentido, sua análise fundamentou-se em dois momentos principais: 1) entender os efeitos do cenário de modernização social e prosperidade do capitalismo pós-guerra e como este produziu uma imensa liberação cultural, com o desprendimento de novas energias 
sociais e o sentimento generalizado de que "tudo era possível"; e 2) compreender como a irrupção da crise econômica mundial nos anos 1970, junto a outros eventos históricos, levaram ao "fim dos anos 1960 ", de forma que o sentimento de liberdade que marcou este período fosse dissipado e os problemas da infraestrutura "voltassem a pesar" novamente (JAMESON, 1992b, pp. 125-126). Com isso, Jameson propõe, portanto, um ponto de vista alternativo às visões simplesmente celebratórias ou derrotistas sobre o sentido e significado desta década.

Para o autor, os anos 1960 são, portanto, um marco fundamental para a periodização do capitalismo contemporâneo na medida em que dão início a uma série de rupturas com o projeto moderno em termos políticos, culturais e econômicos, além de gestar um dos fenômenos que propriamente fomentariam o surgimento da pós-modernidade como um momento social e histórico: o processo de dissolução da autonomia característica que as esferas da vida tinham na modernidade - fenômeno nomeado por Jameson de "desdiferenciação", movimento que abole as fronteiras existentes entre o cultural, econômico, político, etc. ${ }^{4}$

Tais argumentações são apresentadas de maneira concisa em Periodizando os anos 60 (1984). No ensaio, o autor articula uma narrativa histórica do período, mas não no sentido tradicional, de como ele "realmente aconteceu"; sua descrição propõe uma reorganização dos procedimentos convencionais de análise histórica, sendo formada essencialmente por quatro níveis distintos - a filosofia, a política, a cultura e a economia - vistos como "fios da narrativa", semiautônomos, que, ao se entrecruzarem, apresentam um modelo de periodização histórica da década (JAMESON, 1992b, pp. 82-84).

4 "A modernidade, como nos foi ensinado por Luhmann, consiste em uma crescente diferenciação, na relativa autonomização de toda uma gama de níveis e atividades sociais de uma para outra: a 'liberação' da cultura do sagrado, por exemplo, ou a 'liberação' da política da ética" (JAMESON, 1997, p. 117). 
Além disso, ao longo dessa narrativa, Jameson se propõe a responder a dois problemas teóricos: 1) a questão a respeito da validade da análise marxista num "período cujas categorias políticas ativas já não pareciam ser as de classe social e em que, de maneira geral, as formas tradicionais da teoria e da prática marxista pareciam ter entrado em 'crise"'; 2) o problema em torno da possibilidade de se formular uma teoria totalizante, capaz de relacionar, de maneira coerente, realidades e fenômenos de ordens aparentemente distintas (JAMESON, 1992b, pp. 121-122).

\section{Da política de classes às políticas de identidade: a desconexão entre as partes e o todo}

O ponto de partida da periodização de Jameson é o terreno político, a partir do mapeamento dos eventos e experiências que ocorreram, sobretudo, nos Estados Unidos, na França e no "Terceiro Mundo". Para ele, entre os acontecimentos que sinalizaram o "nascimento convulsivo daquilo que viria a ser conhecido mais tarde como os anos 60", e que serviram de inspiração para os modelos de resistência política que viriam a surgir no mundo todo, estariam os movimentos anticoloniais surgidos na África inglesa e francesa - independência da Gana (1957), independência das colônias francesas ao sul do Saara (1959), Revolução Argelina (Batalha de Argel, 1957) - além da Revolução Cubana (1959) e suas inovações políticas. ${ }^{5}$

Jameson, portanto, parte de um ponto de vista retrospectivo para defender que as lutas que aconteceram na periferia do capitalismo no final dos anos 1950 nutriram a ideia de libertação

\footnotetext{
${ }^{5}$ Para Jameson, a experiência cubana teria apresentado a construção de um novo modelo revolucionário, a "teoria do foco", diferente tanto do leninismo quanto do maoísmo, caracterizada por um estilo de prática política - a guerrilha - que não corresponderia nem ao modelo tradicional da luta de classes urbana, nem à experiência de movimento de massas camponesas, além de criar um novo "sujeito revolucionário", o guerrilheiro, identificado nem com proletário, nem como camponês (JAMESON, 1992b, pp. 115-119).
} 
daqueles que seriam igualmente "colonizados" internamente no chamado "Primeiro Mundo" - as "minorias, os marginais e as mulheres" - dando aos poucos vida à retórica de autodeterminação de grupos e identidades coletivas, que iria romper com modelos "clássicos" ou modernos de se fazer política (JAMESON, 1992b, p. 85) e alimentar o desenvolvimento do que posteriormente ficou conhecido na história da esquerda ocidental como a New Left ("Nova Esquerda"). Apesar de designar uma gama bastante ampla de fenômenos e formações políticas, pode-se dizer que este termo abarca o conjunto de movimentos que irromperam durante os anos 1960 em diversos países - a defesa dos direitos civis, a luta feminista, estudantil, ecológica, pela libertação nacional, contra a segregação racial, pela liberdade sexual - e que se pretendiam uma terceira via em relação ao déficit democrático do "marxismo oficial" ligado aos Partidos Comunistas e às limitações da socialdemocracia, conformando o que muitos chamaram de "virada cultural". ${ }^{6}$

No cenário norte-americano, o desenvolvimento da New Left esteve vinculado à expansão da luta por direitos civis e dos movimentos de contracultura, que gerou a proliferação de uma série de grupos (estudantis, anti-guerra, feministas, negros etc.), e cujo ápice foi o ano de 1968, que contou com rebeliões urbanas e atos massivos em todo o país. Com o assassinato de Martin Luther King e John Kennedy e com a vitória de Richard Nixon nas eleições presidenciais, assistiu-se, entretanto, a uma gradual virada nos rumos e no caráter destes movimentos. Em especial, após a deflagração do escândalo de Watergate e a retirada das tropas norte-americanas do Vietnã em 1973, houve a dispersão e o esmaecimento de suas energias radicais (GOSSE, 2005, p. 35). Nesse sentido, a efervescência dos anos 1960 aos poucos deu lugar a uma atmosfera de resignação que marcaria os anos 1980: a mesma geração que se contagiou com a esperança advinda da

${ }^{6}$ Como explica Ellen Wood (1995, p. 24), "as várias 'novas esquerdas' compartilhavam um compromisso com as lutas emancipatórias para além - ou pelo menos em adição à - luta de classes tradicional, especialmente os movimentos estudantil, contra a guerra do Vietnã e de libertação negra". 
$|8|$

Jameson e o pós-modernismo

radicalização das lutas, se confrontou com o declínio das mesmas. ${ }^{7}$ Com isso, houve um processo de reversão: o caráter anti-sistêmico característico das ações e teorias em voga naquele período terminou por se traduzir em críticas com temáticas específicas e formas de resistências isoladas.

Assim, subjacente ao prestígio que os ideários comunistas detinham na maior parte dos processos de resistência dos anos 1960, uma nova modalidade política e discursiva passou a ganhar corpo, dando forma a práticas não enquadradas em ortodoxias e desorbitadas dos Partidos Comunistas (OTA, 2016, pp. 54-55). Como observa Paulo Arantes (1990, p. 90), esse deslocamento é visível também em boa parte da teoria social pós-1968, que passou, então, a girar

[...] em torno dos mencionados e assim chamados Novos Movimentos Sociais e em função deles remodelou a imagem da Revolução, dos Intelectuais, das relações entre Teoria e Prática etc., e mais, conforme definhava o impulso globalizante do gauchismo original, delineava-se o horizonte mais modesto [...] de um "reformismo radical" em permanente litígio com a afluência desregulada do capitalismo avançado porém deslegitimado.

\footnotetext{
7 Ativistas reagiram a esse processo de formas diferentes. No caso norteamericano, além da integração de militantes ao quadro do Partido Democrata, houve aqueles que tomaram posições mais céticas, denotando não as vitórias do período (como a legalização do aborto, os avanços contra a discriminação racial e sexual, o fim da guerra, etc.), mas o fracasso dos movimentos, que não conseguiram construir um projeto revolucionário unificado à altura das necessidades de mudança radical da sociedade. Junto a esse processo, uma nova direita também se fortaleceu, aliando conservadorismo econômico e a oposição às lutas no âmbito dos costumes, o que culminou nos anos 1980 na chamada era Reagan. Em meio a isso, "a imagem ou a esperança da revolução foram murchando no Ocidente", cancelando "por todo um período histórico qualquer perspectiva realista de uma destruição do capitalismo avançado pelo socialismo", como narra Perry Anderson (1986, p. 11).
} 
Assim, um dos problemas investigados por Jameson nesse primeiro âmbito da análise - o político - é como se deu essa gradual perda de prerrogativa da perspectiva emancipatória clássica entre os círculos da nova esquerda, que foi concomitante e proporcional à "emergência de uma grande variedade de práticas políticas de pequenos grupos, sem base em classe social": os "movimentos micropolíticos (de vizinhança, de raça, étnicos, de gênero e ecológicos)" (JAMESON, 1997, p. 177, 322). Na visão do autor, o surgimento de "novos personagens coletivos" e novas formas de ativismo provocou uma revisão das categorias prévias da ordem do agente (como a concepção de classe), por elas não acomodarem as experimentações multiformes dos novos antagonismos políticos, que a princípio não se enquadravam no modelo dicotômico da luta de classes, nem seriam oriundos do conflito entre capital e trabalho. Assim, a crescente força social das mulheres, dos negros, dos colonizados e dos estudantes suscitou uma "crise do sujeito", ou melhor, a ideia de uma multiplicação dos sujeitos, e de que as formas de resistência política não advinham mais de apenas um setor - o proletariado industrial - mas também de grupos até então excluídos das reflexões dominantes do marxismo sobre o sujeito histórico. Tal constatação gerou, por sua vez, a dilatação da noção de emancipação para além da reflexão sobre as formas de dominação baseadas na exploração econômica, abrindo espaço para um novo domínio de teorização e atuação centrado com maior força na ideia de dominação cultural e em novos meios de expressão (pautados nas noções de gênero, raça, sexualidade, nacionalidade) (JAMESON, 1992b, p. 125).

Assim, diante do questionamento dos conceitos clássicos marxistas, outras categorias passaram a ser utilizadas, como a noção de "grupo" e de "identidade". Para Jameson, a ideia de adesão a um determinado grupo tornou-se uma espécie de "versão pós-moderna" da consciência de classe, ou ainda, a identificação ideológica com uma classe foi substituída pela filiação a um grupo (JAMESON, 1997, pp.325-326). Nessa lógica, passou-se a privilegiar o desejo de pertencimento a um grupo social (que proporcionaria uma espécie de "gratificação de identidade") em detrimento da 
aderência a organizações políticas como os sindicatos e partidos (que corresponderiam propriamente ao processo de formação da consciência de classe, ou mesmo, de identidade com uma classe), tornando os grupos e a luta por reconhecimento um espaço de atuação próprio, apartado da luta de classes (JAMESON, 1992b, p. 98). ${ }^{8}$ Para Jameson, isso fez emergir um novo espaço político, articulado por slogans como "o pessoal é político", pela retórica do poder, da dominação e do direito ao discurso ${ }^{9}$, que, apesar de ter gerado implicações políticas relevantes, representaria um deslocamento, ou uma substituição estratégica problemática, do econômico para o político:
É claro que é politicamente importante "contestar" as várias formas de poder e dominação: estas últimas, contudo, não podem ser compreendidas a menos que suas relações funcionais com a exploração econômica sejam articuladas (JAMESON, 1992b, p. 90).

Assim, por mais que o cenário aberto pelos anos 1960 tenha tornado de fato necessária uma atualização das concepções clássicas da política emancipatória marxista, elas continuariam fornecendo ferramentas analíticas fundamentais para a interpretação das contradições sociais e das diversas formas de opressão. Nesse sentido, na visão de Jameson, as ponderações e críticas direcionadas ao arsenal marxista teriam mais lastro no sentido institucional do que intelectual, já que elas eram no fundo um reflexo não de uma

\footnotetext{
${ }^{8}$ Em diagnóstico bastante semelhante, Nancy Fraser (2006, p. 231) sintetiza: "a identidade de grupo suplanta o interesse de classe como o meio principal de mobilização política. A dominação cultural suplanta a exploração como a injustiça fundamental. E o reconhecimento cultural toma o lugar da redistribuição socioeconômica como remédio para a injustiça e objetivo da luta política".

${ }^{9}$ As formulações de Foucault foram particularmente importantes no sentido de articular filosoficamente esse novo espaço político, com a proliferação da visão da sociedade como uma multiplicidade irredutível de relações de poder (CALLINICOS, 2008, p. 85).
} 
deficiência teórica da ideia de classe, mas antes de uma crise ou saturação das instituições clássicas através das quais a política marxista de classe se expressava, como os sindicatos e os Partidos Comunistas. Ou ainda, ao ver de Jameson, tais ponderações e críticas decorreriam de explanações mistificadoras, como a de que o declínio de perspectivas tradicionais de esquerda se deveria ao próprio desaparecimento das classes sociais enquanto tais, algo constatado a partir do impacto da "reestruturação global da produção e [d]a introdução de tecnologias radicalmente novas" nos anos 1970 - "que arrancaram trabalhadores das velhas fábricas e de seus empregos, deslocaram novos tipos de indústria para lugares inesperados no mundo e recrutaram uma força de trabalho diferente das tradicionais em muitos aspectos, do gênero à habilidade e nacionalidade" - dando a impressão de uma extinção da figura do trabalhador industrial clássico (JAMESON, 1997, pp. 322-323)..$^{10}$

A saída apresentada pelo autor é, então, um retorno a Lukács para avaliar como, no fundo, essa (falsa) polêmica sobre a prioridade política (ou seja, sobre o que em última instância é o mais

${ }^{10} \mathrm{Ou}$ seja, o descrédito na ideia do proletariado como sujeito revolucionário teve relação também com as próprias mudanças infraestruturais que afetaram as sociedades industriais no pós-guerra. Nos países industrializados, os operários de "chão de fábrica", "que constituíam o núcleo central dos movimentos dos trabalhadores, perdia terreno em termos relativos, e às vezes absolutos, em face de outros setores da população ocupada"; somado a isso, a "coesão das comunidades operárias", elemento tão importante para determinar "a força dos partidos e dos movimentos de massa do proletariado", estava sendo enfraquecidas pela melhoria de vida, pela pressão da publicidade comercial sobre os seus desejos enquanto consumidores, etc. (HOBSBAWM, 1989, p. 39). Assim, o aumento da dessindicalização e o descrédito aos organismos tradicionais "que contribuíram para dar corpo às classes sociais e para conferir-lhes existência objetivada" (como os partidos) conduziu alguns analistas a considerar a análise marxista baseada na classe como obsoleta (BOLTANSKI; CHIAPELLO, 2009, p. 286). Nos anos 1970, surgiram, assim, uma série de conclusões apressadas de declínio da classe tal como desenhada nos autores clássicos, devido as novas características trazidas com a reestruturação capitalista (Wood, 1998, p. 4). 
determinante, a "dominação" política ou a "exploração" econômica?) se deu, primeiramente, por uma leitura equivocada das implicações filosóficas do conceito de classe. O autor enfatiza a necessidade de se retomar a defesa que Lukács faz da prioridade do ponto de vista do proletariado, para demonstrar como a concepção marxista não implica a "preferência" abstrata do conceito de classe sobre outros conceitos "concorrentes" ou outras "instâncias determinantes" (como raça, gênero etc.), mas sim a consideração sobre a importância da experiência do sujeito a partir do lugar específico que ocupa na totalidade social (JAMESON, 2009, pp. 214-215).

Assim, no esforço de dialogar com os debates abertos nos anos 1960, Jameson propõe não uma defesa ao pé da letra da concepção de Lukács sobre o proletariado industrial como agente histórico, nem seu abandono, mas a necessidade premente de fazê-la reemergir conceitualmente numa nova forma. ${ }^{11} \mathrm{O}$ autor considera que, se a ênfase dada em História e Consciência de Classe ao proletariado industrial talvez tenha se tornado em certos aspectos "desatualizada", sua noção de "ponto de vista" teria um papel epistemológico fundamental. Dessa forma, no momento contemporâneo, dever-se-ia agregar à defesa do ponto de vista do proletariado as experiências dos diferentes grupos sociais (isto é, das mulheres, dos negros, colonizados, LGBTs etc.), sem, no entanto, deixar de entendê-los como parte de uma classe. Tendo em vista que cada posição na totalidade social corresponde a formas específicas de opressão e exploração, seu

\footnotetext{
${ }^{11}$ Assim, propõe que "ser consequente com o modelo de Lukács" implicaria ler ou reescrever História e a Consciência de Classe incluindo uma descrição dos fenômenos da consciência e da práxis em suas formas atuais; nesse sentido, o ponto de vista do proletariado não deveria ser visto como um ponto final, uma solução acabada, mas o começo para se pensar essas novas formas (JAMESON, 2009, pp. 218-222). Para sustentar seu argumento, Jameson (2009, p. 222) inclusive reproduz trecho de entrevista que Lukács concedeu nos anos 1960, em que diz: "Hoje, no que tange o despertar do fator subjetivo, nós não podemos recriar e continuar os anos 1920, temos que ao invés disso prosseguir com base em um novo começo, com toda a experiência que temos do movimento operário anterior e do marxismo".
} 
argumento, portanto, é o de que cada grupo acaba enxergando "características do mundo que permanecem obscuras, invisíveis ou meramente ocasionais e secundárias para outros grupos", o que produz novas possibilidades de conhecimento e também de atuação contra o sistema (JAMESON, 2009, pp. 215-216). O autor usa, assim, o exemplo da "teoria do ponto de vista" desenvolvida pelo feminismo (como nos trabalhos de Nancy Hartsock, Dorothy Smith), que teria contribuído para uma atualização da teoria de Lukács ao evidenciar a "experiência fenomenológica específica das mulheres na ordem social patriarcal como uma submissão estrutural igualmente 'excepcional', mas bem diferente da restrição negativa da classe trabalhadora". O ponto de vista dos negros, igualmente, devido a sua posição específica no todo social, daria acesso às especificidades em torno das experiências do racismo e da escravidão, algo que permitiria entender melhor, inclusive, a compreensão de estágios mais antigos da acumulação capitalista (JAMESON, 2009, pp. 219-220).

É nesse sentido que Jameson qualifica História e Consciência de Classe como um "projeto inacabado", qual seja, o de dissolver e desreificar as interpretações monolíticas e estanques de conceitos como "dominação", "exploração", "opressão", reinserindo-as novamente nas situações concretas em que elas emergem, de forma a montar um novo inventário das diferentes estruturas de experiência

[...] vividas pelos vários grupos marginais, oprimidos ou dominados - os chamados "novos movimentos sociais", tanto quanto as classes trabalhadoras com essa diferença, de que cada forma de privação é reconhecida como produzindo sua própria "epistemologia", sua própria visão específica a partir de baixo, e sua própria reivindicação de verdade específica e distintiva"; um projeto que soará como "relativismo" ou "pluralismo" somente se o objeto comum ausente de tal "teorização" de múltiplos "pontos de vista" - o "capitalismo tardio" - for negligenciada (JAMESON, 2009, p. 221). 
Com efeito, com essa espécie de "multiplicação dos pontos de vista", Jameson amplia a noção de prioridade do proletariado para outros grupos sociais, pressupondo que houve uma mudança na composição dos sujeitos na cena política contemporânea, sem, no entanto, abandonar a perspectiva marxista da totalidade. ${ }^{12}$ Isto, por sua vez, é exatamente o que diferencia sua abordagem de outras teorizações sobre o tema, como a das "políticas de identidade", que se restringem a leituras localizadas das formas de opressão, não priorizando a consideração da experiência dos grupos oprimidos sob a totalidade (capitalismo) - que é exatamente aquilo que permite pensar o problema como algo social, para além de individual. Ao mesmo tempo, em meio ao cenário de descrédito dos ideais e debates estratégicos socialistas, Jameson apresenta uma versão sobre o sujeito da práxis que acaba não resolvendo o problema dos desdobramentos institucionais da política de classes, como a relação entre o processo de tomada de consciência e os partidos, sindicatos, etc.

${ }^{12} \mathrm{Ou}$ seja, Jameson explicita como as categorias de classe, raça, gênero, não são substâncias autônomas ou indiferentes umas às outras, mas momentos de uma mesma totalidade. Ao mesmo tempo, argumenta em favor da existência de uma diferença de status conceitual entre o conceito de classe e as demais noções, já que a primeira é universalizante, constituindo "uma forma de abstração capaz de transcender a individualidade e a particularidade de maneira mais bem-sucedida e mais produtiva, na medida em que o resultado daquela transcendência é pressentido como a abolição da própria categoria" (JAMESON, 2004, p. 94). Nesse sentido, a disputa em torno da prioridade política entre tais conceitos se dá justamente quando as categorias de classe, raça e gênero são pensadas apenas em termos empíricos. Por isso, a "compreensão crescente da necessidade de abarcar tais categorias como uma triangulação", pela qual se estabelece o requisito de que o conceito de classe deve sempre se realizar e se especificar por meio das categorias de gênero e raça. Na visão de Jameson, no momento em que tais conceitos são pensados como categorias e não como dados empíricos, tal operação de entrecruzamento já está implícita e corporificada. Além disso, essa temática de discussão refletiria, em sua opinião, "uma perspectiva bem norte-americana, na medida em que raça e, atualmente, gênero sempre pareceram mais visíveis que classe na experiência dos Estados Unidos" (JAMESON, 2004, p. 95). 
Além disso, tais ponderações demonstram que a questão que de certa forma sintetiza o surgimento do pós-moderno na esfera política, segundo Jameson, é o profundo deslocamento dos problemas universais para os particulares:

\begin{abstract}
Antes a política tentava coordenar as lutas globais e as localizadas e, por assim dizer, dotar a ocasião imediata de luta localizada de um valor alegórico, a saber, o de representar a própria luta geral, encarnando-a no aqui e no agora que ficavam aqui transfigurados. A política funciona apenas quando esses dois níveis podem ser coordenados; caso contrário, eles se separam e se transformam em [...] uma luta facilmente burocratizada, por um lado, e, por outro, em uma série verdadeiramente interminável de questiúnculas regionais, cuja "má infinitude" acaba por ser investida, no pós-modernismo, quando se transforma na única forma da política que restou, em algo como o darwinismo social de Nietzsche, e com a euforia forçada de uma revolução metafísica permanente. Penso que a euforia é uma formação compensatória em uma situação na qual, por algum tempo, a política autêntica (ou "totalizante") não é mais possível; é necessário acrescentar que o que fica perdido em sua ausência é precisamente a dimensão do econômico, ou do sistema, da iniciativa privada e da razão do lucro que não podem ser desafiadas num plano local (JAMESON, 1997, p. 332).
\end{abstract}

As micropolíticas, a retórica da diferença, a substituição da perspectiva de classe pela de adesão a grupos etc., seriam, então, antes de mais nada, índices do que viria a ser um sintoma essencialmente pós-moderno: o esmaecimento de perspectivas concretas e totais e sua substituição pelo "meramente particular" (JAMESON, 1997, pp.332-333). Para Jameson, isso se deu justamente no momento em que a ênfase em formas locais, individualizadas e fragmentadas de resistência passou a substituir a concepção marxista de que uma causa específica ou formas de injustiça só 
poderiam ser realmente atendidas e corrigidas levantando-se "a rede de níveis sociais inter-relacionados numa totalidade, o que pede então a invenção de uma política de transformação social" (JAMESON, 1996, pp. 186; 323-324).

A posição de Jameson não implica, portanto, um retorno nostálgico a uma política de classes mais antiga, nem deve se confundir com um repúdio às demandas específicas que as políticas parciais articulam, mas antes, sugere a ponderação sobre os limites de tomá-las isoladamente. Nesse sentido, o autor propõe que elas são realmente efetivas quando são vistas, ao mesmo tempo, como momentos de uma utopia mais geral de transformação da sociedade como um todo. Sem a simultaneidade dessas dimensões, "a demanda política torna-se reduzida a mais um 'problema' local das micropolíticas desse ou daquele grupo limitado [...], e um slogan que, uma vez atingido, não se conduz adiante politicamente" (JAMESON, 2008, p. 384). Nesse sentido, o autor chega a propor uma "política de alianças":

Os grupos étnicos, os movimentos de bairro, o feminismo e vários grupos de "contracultura" ou de estilos de vida alternativos, a dissidência da classe trabalhadora, os movimentos estudantis, os movimentos de causa única - todos, nos Estados Unidos, têm parecido projetar exigências e estratégias teoricamente incompatíveis entre si e impossíveis de se coordenar sobre qualquer base política. A forma privilegiada pela qual a Esquerda americana hoje pode se desenvolver deve, portanto, ser necessariamente a de uma política de alianças; e essa política é o equivalente prático estrito do conceito de totalização ao nível teórico (JAMESON, 1992a, p. 98).

\section{O fim do modernismo e a mudança de função social da cultura}

Para Jameson, tais mudanças significativas no estatuto das práticas e teorias políticas a partir dos anos 1960 guardariam, por sua vez, analogias com uma série de transformações fundamentais 
que, na mesma época, aconteceram na esfera da cultura e no caráter das manifestações artísticas. Ou seja, longe de ser um fenômeno isolado do domínio político, a emergência sistemática de rupturas com o moderno aconteceu em outros planos sociais, algo a principio evidente pelo fato de que o fim da concepção moderna de vanguarda na política também ocorreu no âmbito das artes.

Revisando as teses de Adorno e Horkheimer, Jameson primeiramente identifica a quebra da conceituada distinção entre alta cultura e cultura de massas - e o desaparecimento virtual da primeira enquanto um lugar que ainda assegurava uma experiência estética genuína, um espaço privilegiado de oposição ao processo de mercantilização da sociedade e a estrutura da arte comercial - como um dos fenômenos principais que caracterizam o âmbito cultural a partir dos anos 1960, algo que também pode ser lido, a partir das caracterizações do autor, como o fim da hegemonia europeia na produção cultural e a nova influência exercida pelos Estados Unidos no campo artístico, nos moldes do alcance de sua indústria cultural e do cenário de intensificação da cultura de massas que acontecia no país naquele momento.

Esse processo teria iniciado com a conversão do alto modernismo num cânon na academia, escolas e museus: até os anos 1960, ele era o principal representante de uma cultura de oposição; com o processo de canonização, houve a perda gradual de seu caráter subversivo, tendo em vista que este se apoiava justamente na recusa e negação de tal institucionalização:

[...] o modernismo antigo ou clássico era uma arte de oposição, surgiu no interior da era de ouro da sociedade do negócio como algo de escandaloso e ofensivo ao público da classe média - feio, dissonante, boêmio, sexualmente chocante. [...] Se subitamente nos voltamos para o dia de hoje, podemos medir a imensidão das mudanças culturais que ocorreram. Não apenas Joyce e Picasso não são mais estranhos e repulsivos, como se tornaram clássicos e agora nos parecem muito mais realistas (JAMESON, 2006a, pp. 41-42). 
Assim, na narrativa construída por Jameson, os clássicos do modernismo foram "tomados, pela geração que desponta na década de 1960, como o sistema estabelecido e o inimigo - mortos, asfixiados, canônicos, esses são os monumentos reificados que devem ser destruídos para que se faça qualquer coisa nova" (JAMESON, 2006a, p. 18). Na medida em que essa percepção foi ganhando corpo, novas formas culturais começam a surgir (JAMESON, 1992b, pp. 106-107). Nesse sentido, testemunhou-se, ao longo da década, um momento extraordinariamente rico em termos de invenção de novas formas artísticas no teatro, literatura, cinema, música, etc., pautadas pela ideia de que a inovação formal também era um tipo de protesto social e político, a exemplo dos happenings, que procuravam "abolir a fronteira e a distinção entre a ficção e o fato, entre a arte e a vida" (JAMESON, 2006b, p. 128). A produção cultural tornou-se, então, mais "aberta", tal como desejavam seus artistas, por meio da destruição dos valores estéticos anteriores. ${ }^{13}$

No entanto, esse processo extremo de "liberação" das amarras do moderno e a constante tentativa de derrubada de fronteiras foi se esmaecendo (muito devido ao grau de experimentalismo que atingiu, não atraindo mais um público que o acompanhasse). Além disso, ele foi absorvido pelo crescimento da reprodutibilidade e comercialização da arte pela indústria cultural, que fez com que cultura de massas e alta cultura começassem gradualmente a se desdobrar uma na outra, de forma a fomentar "uma cultura agora universalizada cuja lógica descreve um continuum da 'arte' para o 'entretenimento'" (JAMESON, 1996, p. 187). Nesse processo, tornou-se cada vez mais difícil traçar uma "linha que separa a alta arte das formas comerciais", na medida em que

${ }^{13} \mathrm{Ou}$ seja, Jameson vê positivamente o fato do pós-modernismo representar um "alívio" ao desbloquear e liberar "uma nova produtividade que estava de algum modo tensionada e congelada, endurecida como um músculo com cãibra, no final do período moderno", já que a ideia de artista como "gênio" e "autêntico" tendia a paralisar e intimidar novas produções (JAMESON, 1997, pp. 317-321). 
[...] boa parte dos recentes pós-modernistas ficou fascinada exatamente por aquela paisagem de anúncios e motéis das avenidas de Las Vegas, pelo Late Show e pelo cinema B de Hollywood, pela chamada páraliteratura, com os seus best-sellers de aeroporto, que se alternam entre as categorias do gótico e do romance, da biografia popular e do mistério de assassinato, da ficção científica e do romance fantástico (JAMESON, 2006a, pp. 18-19). ${ }^{14}$

Assim, começam a aparecer "novos tipos de textos, impregnados das formas, categorias e conteúdos da mesma indústria cultural que tinha sido denunciada com tanta veemência por todos os ideólogos do moderno, de Leavis ao New Criticism americano até Adorno e a Escola de Frankfurt" (JAMESON, 1997, p. 28). Ou seja, a tentativa de destruição dos traços modernistas teve um preço: a substituição de seu "elitismo" desembocou na valorização generalizada do caráter "popular" da cultura de massas, no repúdio ao estilo pessoal de uma obra, na tendência à reciclagem eclética de estilos do passado, na destruição da sua profundidade e aspecto crítico, na superficialidade, etc. Desse modo, apesar de seus diversos exemplares também conterem um certo traço subversivo (como apresentam as manifestações do punk, da cultura das drogas e da pornografia), a arte pós-moderna já não

\footnotetext{
${ }^{14}$ Para Jameson, o surgimento dessa nova configuração cultural fez com que a análise dos exemplares da cultura de massas passasse a ocupar um espaço privilegiado, como índice por excelência dos sintomas sociais do mundo pós-moderno. Com isso se evidencia o quanto o colapso da fronteira entre alta cultura e cultura de massas impôs mudanças significativas também nos procedimentos da crítica cultural. Ao mesmo tempo, reforça o novo estatuto que esta passa a ter, num momento em que a cultura visual e imagética se difundiu por toda a vida social. Em As marcas do visível, Jameson promove um tratamento particular sobre esse tema, analisando exemplares da cultura de massas (como os filmes Poderoso Chefão e Tubarão). Para o autor, apesar de toda produção cultural ser determinada por um viés ideológico, de alguma forma, mesmo a cultura mais massificada, traz consigo um viés utópico, sendo papel do crítico marxista investigá-lo.
} 
era de maneira alguma "de oposição" no mesmo sentido que as manifestações modernas, mas sim, "a própria estética dominante ou hegemônica da sociedade de consumo", servindo "como um laboratório de novas formas e modas, à produção de mercadorias empreendida por esta" (JAMESON, 1992b, p. 107).

Para Jameson, portanto, o sentimento a princípio progressista de desprendimento cultural operado nos anos 1960 produziu múltiplos efeitos reversos. Um deles foi o desenvolvimento de uma cultura do significante e do simulacro (JAMESON, 1997, p. 144). Seguindo Baudrillard e Barthes, o autor identifica, assim, que as formas artísticas pós-modernas representavam de maneira sintomática uma "aventura do signo", ao reproduzirem em suas estruturas internas um processo de profunda dissociação entre significante (veículo material ou imagem, com ou sem palavra escrita), significado (imagem mental, sentido ou conteúdo) e referente (JAMESON, 1992b, pp. 108-109). Como descreve em seu Pós-modernismo, o fenômeno pós-moderno na cultura refere-se justamente ao momento em que

\begin{abstract}
Resta-nos o puro jogo aleatório dos significantes [...] que não mais produz obras monumentais como as do modernismo, mas embaralha sem cessar os fragmentos de textos preexistentes, os blocos de armar da cultura e da produção social, em uma nova bricolagem potencializada: metalivros que canibalizam outros livros, metatextos que fazem colagem de pedaços de outros textos - tal é a lógica do pós-modernismo em geral, que encontra uma de suas formas mais fortes, mais originais e autênticas na nova arte do vídeo experimental (JAMESON, 1997, pp. 112-118). ${ }^{15}$
\end{abstract}

\footnotetext{
15 Seguindo Marcuse, Jameson (1997) defende, entretanto, que o pósmodernismo só consegue passar por esse processo de "desreferenciação" ao preço de "conservar um tênue sentido último desse mundo exterior e externo do qual é réplica e duplicação imaginária". Nesse sentido, se propõe a tarefa de investigar e analisar concretamente a experiência pós-moderna em todas as artes, a fim de captar tais resquícios de realidade.
} 
Ou seja, as manifestações culturais pós-modernas assinalariam um novo patamar da reificação e da lógica da fragmentação que, ao adentrar no domínio da linguagem, promoveu primeiro a separação do signo de seu contexto, e depois passou a penetrar o interior do próprio signo, liberando dessa vez o significante de seu próprio significado. Este segundo momento de dissolução teria sido responsável, então, por gerar um novo tipo de textualidade em todas as artes pós-modernas: a linguagem aleatória de puros significantes, "flutuantes e auto-referentes", resistentes ao significado (JAMESON, 1992b, pp. 113-114). Esta, por sua vez, também expressaria um novo tipo de subjetividade que passou a vigorar nessas novas práticas artísticas, mais impessoais, e que marcam o fim do estilo único (isto é, daquela pincelada singular do artista, tão inconfundível como uma impressão digital, tal como presente nas obras-primas do alto modernismo) (JAMESON, 2006a, pp. 42-43). O resultado dessa "morte do sujeito artístico" seria, então, a "canibalização de estilos do passado" e o jogo aleatório de alusões estilísticas que caracterizam a arte pósmoderna: "em um mundo no qual a inovação estilística não é mais possível, tudo o que resta é imitar estilos mortos, falar através de máscaras e com as vozes dos estilos no museu imaginário" (JAMESON, 2006a, p. 25). ${ }^{16}$

Para Jameson, tais sintomas, longe de serem um problema apenas interno aos mecanismos da linguagem e da arte, consistiria num fenômeno mais amplo, projetando "uma imagem útil do

\footnotetext{
${ }^{16}$ Essa é a definição de Jameson de pastiche, modalidade artística pós-moderna que estaria colonizando o presente cultural e cujo exemplo paradigmático seria o "cinema nostálgico", abundante nas manifestações da cultura de massas, composto por filmes que retratam tentativas de se recuperar um "passado perdido", bem como a atmosfera e as modas típicas de gerações anteriores. Entre seus exemplos, Jameson destaca o American graffiti (1973), de George Lucas (uma nostalgia dos anos 1950), bem como seu Guerra nas Estrelas (1977), que não é um filme histórico sobre o nosso passado intergaláctico, mas a experiência cultural das gerações da década de 1930 e 1950 com os seriados das tardes de sábado; além de Chinatown, de Polansky, e $\mathbf{O}$ conformista, de Bertolucci (ambos formas nostálgicas da década de 1930).
} 
processo de transformação da cultura em geral" (1992b, pp. 109110). Como expressa em Marxismo e forma, "tal arte expressa a realidade americana" e, assim, envolve "um julgamento sobre nós mesmos tanto quanto sobre as obras de arte às quais reagimos" (JAMESON, 1985, pp. 313-14). A percepção mais clara disso seria que esse novo estágio cultural produziria a construção de uma realidade social fragmentada e anárquica, a paisagem-mercadoria característica do capitalismo contemporâneo, completamente estetizada, composta por uma série de imagens e significantes.

Assim, além da modificação do caráter e natureza das produções culturais, a periodização dos anos 1960 é discutida por Jameson em termos de uma mudança de função social da cultura. A cultura teria deixado de ser uma esfera autônoma e se tornado "coextensiva à vida social em geral", de modo que todos os níveis da sociedade do espetáculo, da imagem, do simulacro - "desde as superestruturas aos mecanismos da própria infraestrutura" teriam se tornado culturais (JAMESON, 1992b, p. 115). Assim, ela teria passado por um processo de prodigiosa expansão, "por todo o domínio do social, até o ponto em que tudo em nossa vida social - do valor econômico e do poder do Estado às práticas e à própria estrutura da psique - pode ser considerado como cultural, em um sentido original que não foi, até agora, teorizado" (JAMESON, 1997, p. 74).

De fato, o que aconteceu com a cultura pode muito bem ser uma das pistas mais importantes para se detectar o pós-moderno: uma dilatação imensa de sua esfera (a esfera da mercadoria), uma aculturação do Real imensa e historicamente original, um salto quântico no que Benjamin ainda denominava a "estetização" da realidade (ele achava que isso dava em fascismo, mas nós sabemos que é apenas divertido: uma prodigiosa alegria diante da nova ordem, uma corrida às compras, nossas "representações" tendendo a gerar um entusiasmo e uma mudança de humor não necessariamente inspirados pelos próprios objetos representados) (JAMESON, 1997, p. 14). 
Ou seja, a cultura perdeu a autonomia relativa que antes detinha no período moderno, tornando-se, além de socialmente conveniente, completamente integrada à estrutura socioeconômica. Partindo dessa caracterização, Jameson então reforça a defesa do pós-modernismo como um "enquadramento sugestivo para explicar o que aconteceu com a cultura nos anos 60", iniciando uma agenda de pesquisa que irá desenvolver com mais fôlego no livro Pós-modernismo, a lógica cultural do capitalismo tardio, composta pelo exame dos seguintes temas: a questão da "morte do sujeito"; a natureza e função da "cultura do simulacro" (Baudrillard e Deleuze) e sua relação com a cultura dos meios de comunicação de massas ou a "sociedade do espetáculo" (Guy Debord); o novo status da imagem e da estética da textualidade; a emergência da temporalidade esquizofrênica e o eclipse da profundidade e da historicidade, com o aparecimento do pastiche e da nostalgia - algo que evidencia, por sua vez, como o autor incorpora a teoria marxista elementos provenientes de outras correntes de pensamento (JAMESON, 1992b, pp. 105-106).

\section{A "morte da filosofia" e o advento da Teoria}

Outro evento notadamente pós-moderno elencando por Jameson em sua periodização é o declínio da filosofia e sua substituição por uma nova configuração, a Teoria. Para o autor, isso representou a abolição de uma nova fronteira - aquela que até então separava as diferentes disciplinas acadêmicas - e a produção um novo gênero discursivo - a "teoria contemporânea" - que passou a aglutinar uma série de tendências teóricas bastante diversas, suprimindo a ideia de modelos filosóficos sistêmicos (JAMESON, 2006b, p. 143). Em suas palavras,

Na geração anterior ainda havia um discurso técnico da filosofia profissional - os grandes sistemas de Sartre ou dos fenomenólogos, a obra de Wittgenstein, a filosofia da linguagem comum ou analítica -, à margem do qual ainda se podia distinguir aquele discurso 
bem diferente das outras disciplinas acadêmicas [...] Hoje em dia, cada vez mais, temos um tipo de escrita simplesmente chamada de "teoria", que é, ao mesmo tempo, todas e nenhuma dessas coisas. Esse novo tipo de discurso, geralmente associado à França e à chamada teoria francesa, torna-se então amplamente difundido e marca o fim da filosofia enquanto tal $\left(\right.$ JAMESON, 1997, p. 19). ${ }^{17}$

O surgimento dessa nova configuração teórica seria o reflexo, portanto, de dois fenômenos principais: a crise do cânon dos grandes escritos filosóficos (semelhante a das obras de arte modernistas) e a "morte do sujeito filosófico" (tal como encarnada na figura de Sartre e na sua defesa da vocação política do filósofo nos anos 1960). Com isso, uma "virada" foi processada no âmbito da filosofia: os modelos até então dominantes (como o existencialismo sartriano) foram gradualmente suplantados "por uma variedade de novas tentativas teóricas que compartilham pelo menos uma única experiência fundamental - a descoberta do primado da Linguagem ou do Simbólico" (JAMESON, 1992b, p. 90-94), que inauguraria, então, o momento pós-estruturalista da teoria (associado a nomes como Foucault, Deleuze e Derrida), composto por um novo arsenal baseado no código linguístico e que buscava dar forma e expressão aos novos objetos e sujeitos sociais não-conceituados pelos modelos anteriores. ${ }^{18}$

\footnotetext{
${ }^{17}$ Jameson também toma como exemplo a obra de Michel Foucault: "deve ser chamada de filosofia, história, teoria social ou ciência política?" (JAMESON, 1997, pp. 19-20).

${ }^{18}$ Retomando suas avaliações sobre o estruturalismo em The Prison-House of Language, Jameson avalia como esse giro para a linguagem na teoria contemporânea está relacionado com as próprias condições concretas do momento, já que o "bombardeio de informações e mensagens de todos os tipos na revolução dos meios de comunicação de massa" produzido pela revolução tecnológica nos anos 1970 foi filosoficamente acolhido e conceitualmente expresso por meio dos códigos da linguagem (JAMESON, 1992b, pp. 99-100).
} 
Com essa transformação, o próprio caráter dos textos teóricos mudou radicalmente: o sentido destes não é mais o de buscar uma "inserção nas questões e debates da tradição filosófica", mas sim, a atividade de se gerar novos "códigos" a partir de códigos preexistentes, a prática de misturar arbitrariamente múltiplas alusões disciplinares, de forma que sua coesão se desfaz e "suas referências 'intertextuais' básicas" tornam-se aleatórias: "Mumford ao lado de Antonin Artaud, Kant com Sade, filosofia pré-socrática, o presidente Schreber, um romance de Maurice Blanchot, escritos de Owen Lattimere sobre a Mongólia e um sem-número de obscuros tratados médicos do século XVIII, escritos em latim" (JAMESON, 1992b, p. 103).

Com isso, opera-se "uma dinâmica em que já não há ideias, e sim textos": a filosofia - como sistema coerente de problemas que visava "a descoberta de uma verdade" - é substituída pela teoria, que "concebe sua vocação [...] como luta acerca de formulações puramente linguísticas", numa "perpétua guerra de guerrilha entre os significantes materiais de formulações textuais" (JAMESON, 1992b, p. 105). Assim, a preocupação de se contribuir para o conjunto de questões de um dado sistema filosófico ou visão de mundo é trocada por uma batalha entre "discursos teóricos" e códigos ideológicos, que seriam "a marca de adesão a um grupo, vista de uma perspectiva diferente, mais sociológica" (JAMESON, 1997, p. 391). ${ }^{19}$

${ }^{19}$ Vale notar que, apesar de crítico da Teoria, enquanto um novo espaço enunciativo fluido em termos de métodos e objetos que transcende barreiras disciplinares, Jameson também pode ser visto como um de seus expoentes. Como observa Fabio Durão (2011, p. 27): “O profissional que se move dentro deste novo espaço enunciativo deixa de ser o crítico literário para se tornar o teórico. Seu exemplo maior talvez seja Fredric Jameson, que fez seu doutorado sobre Sartre, escreveu extensamente sobre literatura, mas desde os anos 1980 vem inserindo-se em debates sobre cinema, linguística, arquitetura, economia, vídeo, psicanálise, filosofia e, é claro, a própria Teoria. Onde encaixar, por exemplo, seu Pós-modernismo, ou a lógica cultural do capitalismo tardio (1996)? Em que configuração disciplinar tradicional poderia ser inserido? (...) a variedade de campos mobilizados pela teoria americana obriga que surja um 


\section{Um novo estágio do capitalismo}

Jameson finaliza sua periodização com o exame das transformações na esfera econômica, que, segundo ele, seriam decisivas para a consolidação do pós-modernismo enquanto uma lógica cultural. $\mathrm{O}$ autor apresenta a hipótese de que um conjunto de eventos ocorridos entre $1972-1974^{20}$ sinalizavam não só o encerramento definitivo dos anos 1960, como uma reestruturação geral no âmbito do modo de produção capitalista. E o episódio determinante, nesse sentido, teria sido a crise econômica mundial em 1973, responsável por colocar um "ponto final à expansão econômica e à prosperidade características do pós-guerra e dos anos 1960 em particular" (JAMESON, 1992b, pp. 116-120).

Jameson parte da definição de "capitalismo tardio", exposta por Ernest Mandel (1982), para defender um terceiro estágio do desenvolvimento capitalista teria sido inaugurado, ou ainda, uma forma mais pura e homogênea de capitalismo, mais perto da descrição de Marx, na qual a expansão prodigiosa do capital atingiu um grau nunca antes visto, penetrando áreas que até então não haviam sido atingidas pelo sistema.

[...] o capitalismo tardio em geral (e os anos $60 \mathrm{em}$ particular) constitui um processo em que as últimas zonas remanescentes (internas e externas) de précapitalismo - os últimos vestígios de espaço tradicional ou não transformado em mercadoria dentro e fora do

espaço que os englobe, e esse espaço é o da própria Teoria".

${ }^{20}$ Entre eles, Jameson cita o declínio do movimento negro e dos movimento pacifista e antibelicista; o encerramento do ciclo contestatório aberto em maio de 1968 e a assinatura do "programa comum" entre o Partido Comunista e Partido Socialista na França em 1972; a ofensiva dos intelectuais associados ao establishment, com ataques ideológicos à cultura e política dos anos 1960; a esquematização de uma nova estratégia global para a afirmação dos interesses dos Estados Unidos; a emergência do conceito de "corporação multinacional"; a militarização dos regimes da América Latina, após o golpe no Chile em 1973 etc. 
mundo avançado - são agora finalmente penetradas e colonizadas por sua vez. O capitalismo tardio pode portanto ser definido como o momento em que os últimos vestígios de natureza que sobreviveram ao capitalismo são finalmente eliminados: a saber, o Terceiro Mundo e o inconsciente. Os anos 60 terão sido então o momentoso período de transformação em que essa restruturação sistêmica se fez em escala global (JAMESON, 1992b, p. 124).

Uma nova fase de expansão capitalista teria sido, portanto, realizada com a colonização final do que seriam os últimos enclaves pré-capitalistas remanescentes de resistência à lógica instrumental do capital - como o "Terceiro Mundo", o Inconsciente e a Natureza. ${ }^{21}$ Além disso, especialmente com a crise de 1973, ela se caracterizaria pela dissipação das energias emancipatórias, promovendo a neutralização e proletarização de todas as forças sociais e formas de resistência cultural que haviam marcado os anos 1960, incorporando-as na própria lógica do sistema. ${ }^{22}$

${ }^{21}$ Por intermédio de Mandel, Jameson defende que a expansão global da forma mercadoria e a ambição crescente do capital de abarcar cada vez mais esferas da vida social em seu processo de desenvolvimento teria atingido seu ápice, de forma que o capitalismo tornou-se um sistema total, ou seja, nada mais existiria "fora do sistema". Dois eventos teriam tornado isso possível: a "Revolução Verde", que foi responsável por reduzir definitivamente a Natureza ao status de mercadoria ao destruir a agricultura pré-capitalista (substituindo as práticas tradicionais de cultivo pela aplicação de novos métodos, com o uso de fertilizantes químicos e experimentações genéticas com plantas); e a Indústria Cultural que, em decorrência da "ascensão das mídias e da indústria da propaganda", teria finalmente penetrado todas as instâncias da consciência humana. A situação descrita por Jameson, nesse sentido, é de uma "modernização totalmente implantada", não havendo mais obstáculos pré-capitalistas a serem superados. Ou seja, a modernidade como desenvolvimento desigual de temporalidades desiguais, ou melhor, como "modernização incompleta", estaria superada. Para uma crítica ao uso de Jameson do termo "capitalismo tardio", ver Davis (1985).

${ }^{22}$ Tal diagnóstico é semelhante ao de Boltanski e Chiapello (2009, p. 199), 
Além do surgimento do neocolonialismo como um novo modelo de dominação, substituto do imperialismo ${ }^{23}$, as universidades (um dos focos da nova esquerda estudantil) passaram por um processo de privatização a partir dessa data; o Estado teve seu poder repressivo renovado; e o reconhecimento das diferentes identidades, a celebração do prazer e dos novos costumes, bem como as reivindicações por liberação do corpo, tornaram-se precisamente meios de manutenção do sistema de consumo, de propaganda e da cultura de massas, despertando desejos capitalistas com novos produtos e novas imagens de anúncios (JAMESON, 1997, p. 328). Assim, a lógica mercantil, que por princípio atua pela produção de novas necessidades e demandas, encontrou na retórica do pluralismo e das diferenças um novo meio de se expandir (JAMESON, 1997, pp. 215-216). A estrutura

que também identificam que o capitalismo se reestruturou nos anos 1970 desarmando a crítica social e estética produzida em 1968. Tal renovação teria representado uma superação tanto do capitalismo quanto do anticapitalismo, na medida em que os traços das revoltas operárias e estudantis (as críticas à alienação, à mecanização, ao poder hierarquizado, ao paternalismo e autoritarismo, as defesas por autenticidade e liberação) e sua linguagem da autonomia e autogestão foram incorporados pelo sistema, para realizar uma reorganização do trabalho, que passou a ser pautado por um modelo mais flexível (BOLTANSKI; CHIAPELLO, 2009, p. 201).

${ }^{23}$ De acordo com Jameson, o capitalismo mudou "a relação com suas colônias, transformando um controle imperialista ultrapassado em penetração de mercado, destruindo as antigas comunidades de aldeia e criando um contingente de mão-de-obra assalariada e um lúmpen-proletariado inteiramente novos" (JAMESON, 1992b, p. 123). Para o autor, isso revela como a visão de que os anos 1960 teriam significado o rompimento com as amarras do imperialismo clássico é na verdade uma "simplificação mítica", pois com o encerramento das lutas por emancipação nacional, o capitalismo produziu uma combinação paradoxal entre descolonização e neocolonialismo, renovando sua prática imperialista (JAMESON, 1992b, p. 92). Isso "mostra como o sentido de liberdade e possibilidade dos anos 1960 foi, ao mesmo tempo, uma realidade objetiva e uma ilusão histórica, ou melhor, "um processo propriamente dialético em que 'liberação' e dominação combinamse inextricavelmente" (JAMESON, 1992b, p. 124). 
de consumo em massa passou, assim, a responder à diversidade das estruturas de opressão (classe, gênero, etnia, nacionalidade), criando novos nichos de mercado.

A partir desse conjunto de caracterizações, Jameson argumenta que a centralidade adquirida pela cultura a partir dos anos 1960 é uma das características definidoras do capitalismo contemporâneo. Para o autor, ela tornou-se crucial em termos econômicos e ideológicos para o sistema, ao adquirir proeminência como elemento de legitimação da acumulação capitalista, na medida em que, mais do que nunca, o sistema dependeria de uma lógica cultural para o seu funcionamento e reprodução, seja na condição de um ramo da economia (a indústria cultural, a grande mídia, etc.), ou como marco de todo um conjunto de comportamentos e valores sociais, novos tipos de consumo, moda e obsolescência planejada. ${ }^{24} \mathrm{Ou}$ seja, pelo fato do sistema depender de uma forma ainda mais sofisticada de dominação cultural para garantir seu processo de desenvolvimento.

Desse modo, o famoso deslocamento atribuído ao marxismo ocidental das preocupações tradicionais com a economia política para a cultura (ANDERSON, 2004) se justifica na obra de Jameson pelo fato de que as modificações na esfera cultural são para ele um ponto de vista privilegiado para compreender o funcionamento do sistema capitalista como um todo. Ou melhor, porque, com a penetração e generalização da forma-mercadoria para todas as instâncias da vida, um dos traços característicos do período moderno - a diferenciação dos níveis sociais - é dissolvida, de forma que economia e cultura tornam-se coexistentes. Nesse sentido, o autor passou a defender uma análise que não procede a separação

${ }^{24}$ Segundo Jameson, os mecanismos da inovação e criatividade estéticas passaram a ter uma função estrutural essencial no capitalismo diante da necessidade incessante de produzir novas mercadorias para consumo com uma aparência cada vez mais nova. Assim, as imagens, as representações e os mecanismos próprios à esfera cultural se tornaram uma área de atuação fundamental da produção, visível a partir da importância que assumiram a propaganda, a mídia e a indústria cultural no mundo atual. 
das esferas cultural e econômica; em sua concepção, uma descrição infraestrutural deve ser necessariamente uma descrição cultural, e vice-versa, num "circuito de realimentação", de forma que a noção de pós-modernismo traz sempre embutida a de capitalismo tardio (JAMESON, 1997, 18-19).

Dizer que meus dois termos, o cultural e o econômico, se fundem desse modo um no outro e significam a mesma coisa, eclipsando a distinção entre base e superestrutura, [...] é o mesmo que sugerir que a base, no terceiro estágio do capitalismo, gera sua superestrutura através de um novo tipo de dinâmica. E isso [...] parece nos obrigar, de antemão, a tratar os fenômenos culturais no mínimo em termos de business, se não nos termos da economia política (JAMESON, 1997, p. 25).

Por isso, para Jameson, o pós-modernismo não é uma categoria estritamente cultural: é um termo de periodização, usado para nomear um estágio do desenvolvimento capitalista em que tudo se tornou sistêmico e em que a produção cultural passou a ter um lugar específico.

\section{Os sintomas sociais pós-modernos}

A caracterização sobre a esfera econômica encerra, portanto, a periodização de Jameson, cuja exposição se pauta em três momentos fundamentais: 1) a década de 1960, marcada pelo aparecimento gradual das primeiras manifestações pósmodernas na política, cultura, teoria, etc.; 2) a crise de 1973, que data uma mudança de natureza do capitalismo enquanto sistema e modo de produção; 3) os anos 1980, momento propriamente de consolidação e auge do pós-modernismo, em que há a cristalização das mudanças ocorridas nas diferentes esferas sociais da vida.

Em Pós-modernismo, a lógica cultural do capitalismo tardio, Jameson refina sua proposta de periodização, priorizando 
agora a atmosfera cultural e política dos anos 1980. Ou seja, o autor deixou de rastrear as condições e eventos históricos que tornaram o pós-modernismo possível, e passou a abordá-lo em sua forma final. Para isso, Jameson aplica um método que alia mais fortemente crítica cultural e análise histórica, de forma que o centro de suas reflexões teóricas passa a ser o exame de uma série de exemplares das teorias e produções culturais pós-modernas (cinema, arquitetura, artes visuais, literatura, música etc.), que, segundo ele, dariam, por sua vez, acesso à compreensão de aspectos essenciais da vida social. Nesse sentido, o autor constrói um modelo interpretativo que articula os diferentes fenômenos culturais com a realidade mais ampla do capitalismo tardio, retomando, assim, o esquema que havia apresentado em $\mathbf{O}$ inconsciente político, segundo o qual os produtos culturais teriam a capacidade de servir como um índice e como uma imagem alegórica de uma época - algo que seria ainda mais intensificado na pós-modernidade, já que essa de certa forma teria aumentado a identidade entre a arte e a estrutura do capitalismo. ${ }^{25}$

${ }^{25}$ Jameson analisa, por exemplo, obras de Andy Warhol, o Hotel Bonaventure, o gênero de "filmes nostalgia" (como Guerra nas Estrelas, de Georg Lucas), a produção literária do escritor E. L. Doctorow, o pensamento de JeanFrançois Lyotard, etc., o que constata uma dilatação profunda do espectro das análises de suas obras anteriores, sobretudo devido à avaliação de que a literatura não constituía mais a forma central da cultura capitalista. Ao selecionar esses exemplares para análise, Jameson, contudo, nota que eles não são "ilustrações" por excelência do pós-modernismo, pois, diferentemente do período moderno, em que existiam "obras-primas" e cânones exemplares, no momento pós-moderno estes são substituídas por "textos" que não possuem mais exatamente uma lógica comum. $\mathrm{O}$ vídeo, nesse sentido, teria se tornado a forma de arte por excelência do capitalismo tardio: "É voz corrente que toda era é dominada por um gênero, ou forma privilegiada, cuja estrutura parece ser a forma mais adequada para exprimir suas verdades secretas" (JAMESON, 1997, p. 91). Ele substitui o papel antes cumprido pela literatura e cinema, tornando-se a forma de arte ou médium que melhor expressa as características do pós-modernismo (relação espaço-tempo, simulacro, poder da imagem etc.) e o atual estágio de desenvolvimento tecnológico da sociedade contemporânea 
Assim, a partir da operação interpretativa do inconsciente político de textos e objetos da cultura da época, Jameson oferece um inventário com as principais características e traços constitutivos do pós-modernismo, que podem ser entendidos como sintomas sociais do próprio capitalismo em seu terceiro estágio de desenvolvimento: 1) a falta de profundidade, presente tanto na superficialidade da argumentação dos teóricos pós-modernos (em suas práticas discursivas sincrônicas, que repudiam modelos de compreensão histórica e, portanto, flutuam na superficialidade do presente), como na cultura da imagem (de maneira não apenas metafórica, mas também física e visual, como demonstram suas análises da arquitetura pós-moderna, que suprimiram a noção de dimensionalidade); 2) o enfraquecimento da historicidade e a presentificação, cuja maior manifestação é o desenvolvimento de uma "consciência esquizofrênica" (pautada na falta de clareza do sujeito em relação ao passado-presente-futuro) e na dificuldade de imaginação de um futuro radicalmente diferente; 3) o esmaecimento dos afetos e o surgimento de um novo tipo de matriz emocional (o das "intensidades", esquizofrenia, euforia e badtrips que substituem os sentimentos de alienação, anomia, solidão, ansiedade, neuroses e histerias do sujeito centrado), profundamente relacionado aos novos fenômenos tecnológicos e à ideia de "morte do sujeito"; 4) o aparecimento de mutações na experiência espaço-tempo, que expressam a redução do tempo ao presente, ou melhor, ao "aqui e agora", ao que está ao nosso redor (o espaço), tornando as experiências dos indivíduos fundamentalmente presentificadas e espaciais; e 5) a primazia da representação e da imagem, responsável por colocar em outro patamar o fenômeno de reificação capitalista descrita por Lukács, que se utilizaria também de imagens, e não exclusivamente de objetos, como suporte material.

Jameson apresenta, portanto, como o desenvolvimento avassalador do capitalismo, representado em diferentes

(computador, informação etc.), que foi, inclusive, o que o tornou possível (JAMESON, 1997, p. 99). 
exemplares das produções culturais e artísticas pós-modernas, configurou sintomas sociais e subjetivos profundos - entre eles, a predominância do espaço como a categoria que passou a organizar a nossa experiência social na globalização e uma intensa mutação do sujeito, que tornou-se existencialmente aprisionado ao presente e teve sua integridade psíquica perdida no momento em que ela virou uma "montanha russa" que oscila da euforia consumista à depressão (JAMESON, 1997, p. 29). Em sua visão, o mundo do consumo, da propaganda, da mídia e dos significantes aleatórios tornaram a realidade em pura aparência (estética, fetichizada e libidinizada), alimentando um tipo de subjetividade altamente danificada, ao torná-la um "repositório de imagens e de simulacros" (JAMESON, 1997, p. 45, 143). Isso teria produzido um "sujeito esquizofrênico", que perdeu seu senso de totalidade, bem como o complexo temporal e sua capacidade de organizar passado e futuro numa experiência coerente, fenômeno que está exemplificado nas próprias produções culturais pós-modernas (que se tornaram "um amontado de fragmentos" aleatórios).

Apesar do debate pós-moderno ter há tempos se encerrado ${ }^{26}$ e não ter se traduzido por completo no contexto brasileiro ou latinoamericano - haja visto que nosso problema, enquanto periferia do capitalismo, passava por compreender, antes de mais nada, se haveríamos conhecido plenamente a própria modernidade - podese dizer que alguns problemas por ele tematizados de certa forma persistem hoje, sobretudo enquanto um tipo de subjetividade e um fenômeno social das grandes cidades globais, sendo ainda

\footnotetext{
${ }^{26}$ Após o esgotamento das discussões sobre o pós-modernismo, o próprio autor faz uma revisão crítica da sua utilização do termo (ver JAMESON 2015; 2016). Como bem lembrado por Hobsbawm (1989, p. 63), "as modas intelectuais mudam e muda o ponto de equilíbrio no debate entre os estudiosos", algo bastante verdadeiro em Jameson, já que a própria estrutura de seu pensamento, orientada pela crítica dialética, baseia-se invariavelmente nas referências que norteiam os debates em voga para se desenvolver. $O$ novo conceito que viria a tomar a discussões posteriormente foi o de globalização, adotado por Jameson nos anos 1990, e que serviu para corrigir alguns aspectos de suas formulações anteriores.
} 
possível extrair contribuições para pensar as implicações do desenvolvimento capitalista e de uma sociedade cada vez mais rodeada e saturada de imagens, formas de consumo, tecnologias, mídias, cultura de massas etc. Ou ainda, num contexto em que a fragmentação das formas de conhecimento, das práticas políticas e da própria experiência social continuam vigentes, perspectivas totalizantes como as de Jameson seguem sendo imprescindíveis para uma compreensão coesa da vida social, em seu esforço de reconectar as partes e o todo.

\section{Referências}

ANDERSON, P. Modernidade e revolução. Novos estudos CEBRAP, São Paulo, n. 4, pp. 2-15, 1986.

ANDERSON, P. Considerações sobre o marxismo ocidental. São Paulo: Boitempo, 2004.

ARANTES, P. Tentativas de identificação da Ideologia Francesa. Novos Estudos, n. 28, v. 3, out 1990.

BOLTANSKI, L. \& CHIAPELLO, È. O novo espírito do capitalismo. São Paulo: WMF Martins Fontes, 2009.

CALLINICOS, A. Whither Anglo-Saxon Marxism?. Em: BIDET, J. \& KOUVELAKIS, S. (eds.). Critical Companion to Contemporary Marxism. Boston: Brill, 2008.

DAVIS, M. Urban renaissance and the spirit of postmodernism. New Left Review, n. 151, May-June, pp. 106-113, 1985.

DURÃO, F. A. Teoria (literária) americana: uma introdução crítica. São Paulo: Autores Associados, 2011.

FRASER, N. Da distribuição ao reconhecimento? Dilemas da justiça numa era "pós-socialista". Cadernos de campo, São Paulo, n. 14/15, pp. 231-239, 2006.

GOSSE, V. The Movements of the New Left (1950-1975): A Brief History with Documents. Boston: Bedford/St. Martin, 2005. 
HOBSBAWM, E. O marxismo hoje: um balanço aberto. Em: HOBSBAWM, E. (org.). História do marxismo - Vol. 11: O marxismo hoje (primeira parte). Rio de Janeiro: Paz e Terra, 1989.

JAMESON, F. The prison-house of language: a critical account of structuralism and russian formalism. Princeton: Princeton University Press, 1974.

JAMESON, F. Marxismo e forma. São Paulo: Hucitec, 1985.

JAMESON, F. O inconsciente político. São Paulo: Ática, 1992a.

JAMESON, F. Periodizando os anos 60. In: HOLLANDA, Heloísa Buarque de (org.). Pós-modernismo e política. Rio de Janeiro: Rocco, $1992 b$.

JAMESON, F. As marcas do visível. Rio de Janeiro: Graal, 1995.

JAMESON, F. O marxismo tardio: Adorno ou a persistência da dialética. São Paulo: Ed. Unesp, 1996.

JAMESON, F. Pós-modernismo, a lógica cultural do capitalismo tardio. São Paulo: Ática, 1997.

JAMESON, F. O marxismo realmente existente. Em: JAMESON, F. Espaço e imagem: teorias do pós-moderno e outros ensaios. Rio de Janeiro: Editora UFRJ, 2004.

JAMESON, F. Pós-modernismo e sociedade de consumo. Em: JAMESON, F. A virada cultural: reflexões sobre o pós-moderno. Rio de Janeiro: Civilização Brasileira, 2006a.

JAMESON, F. "Fim da arte" ou "Fim da história"?. Em: JAMESON, F. A virada cultural: reflexões sobre o pós-moderno. Rio de Janeiro: Civilização Brasileira, 2006b.

JAMESON, F. Pleasure: a Political Issue. Em: JAMESON, F. The Ideologies of Theory. London: Verso, 2008.

JAMESON, F. "History and Class Consciousness" as an Unfinished Project. Em: JAMESON, F. Valences of the Dialectic. London: Verso, 2009. 
JAMESON, F. The aesthetics of singularity. New Left Review, 92, March-April, 2015.

JAMESON, F.; BAUMBACH, N.; YOUNG, D.; YUE, G. Revisiting Postmodernism: an interview with Fredric Jameson. Social Text, 127, v. 34, n. 2, pp. 143-160, junho 2016.

LUKÁCS, G. História e Consciência de Classe: estudos sobre a dialética marxista. São Paulo: Martins Fontes, 2003.

MANDEL, E. O capitalismo tardio. São Paulo: Abril Cultural, 1982.

OTA, N. A quarta parede do marxismo francês: maio de 68 e a invenção dos dispositivos intelectuais de engajamento. Dois pontos, v. 13, n.1, pp. 53-72, 2016.

WOOD, E. M. A chronology of the New Left and its successors, or: who's old fashioned now? Socialist Register, v. 31, pp. 22-49, 1995.

WOOD, E. Capitalist change and generational shifts. Monthly Review, v. 50, issue 5, 1998. 